\title{
Extraskeletal myxoid chondrosarcomas do not show a chondrocytic phenotype
}

\author{
Thomas Aigner $^{1}$, André M Oliveira ${ }^{2, *}$ and Antonio G Nascimento ${ }^{2}$ \\ ${ }^{1}$ Department of Pathology, University of Erlangen-Nürnberg, Erlangen, Germany and ${ }^{2}$ Department of \\ Laboratory Medicine and Pathology, Mayo Clinic, Rochester, MN, USA
}

\begin{abstract}
Extraskeletal myxoid chondrosarcoma is a rare mesenchymal soft-tissue malignancy of putative chondrocytic differentiation. Occasional overt cartilage formation, positivity for S-100 protein, and ultrastructural analysis have supported this view. However, most extraskeletal myxoid chondrosarcomas do not show chondroid tissue formation, and S-100 protein is found much less commonly than has been reported. Both these observations cast doubt on the histogenetic classification of extraskeletal myxoid chondrosarcoma as a chondroblastic entity. Mostly using matrix proteins as markers of mesenchymal cell differentiation, we investigated the biochemical matrix composition and cellular phenotype of the tumor cells in representative specimens from 14 extraskeletal myxoid chondrosarcomas. In all but one tumor specimen, which showed histomorphologically overt cartilage formation, only occasional staining for the proteoglycan aggrecan was found. Specimens from two tumors showed presence of collagen type II, and none was positive for collagen type X. Instead, collagen types I, III, and VI were diffusely positive. Also, S-100 protein was largely absent. Our results suggest that the basic cellular phenotype of extraskeletal myxoid chondrosarcoma is not chondrocytic or prechondrocytic and that extraskeletal myxoid chondrosarcoma is not a chondrosarcomatous entity. Extraskeletal myxoid chondrosarcoma consists most likely of primitive mesenchymal cells with focal, multidirectional differentiation. Chondrocytic differentiation is an unusual facet in the spectrum of differentiation patterns exhibited by these lesions.
\end{abstract}

Modern Pathology (2004) 17, 214-221, advance online publication, 5 December 2003; doi:10.1038/modpathol.3800036

Keywords: chondrosarcoma; collagen; differentiation; tumor

Extraskeletal myxoid chondrosarcoma is a rare mesenchymal malignancy. It was first described by Stout and Verner ${ }^{1}$ in 1953 and later in more detail and as a distinct entity by Enzinger and Shiraki ${ }^{2}$ in 1972. Despite older studies that considered extraskeletal myxoid chondrosarcoma a variant of myxoid chondrosarcoma of bone, ${ }^{1}$ later work did not fully support this. ${ }^{3}$ Extraskeletal myxoid chondrosarcoma may occur anywhere outside the bony skeleton, including the synovial membrane and the neurocranium, ${ }^{4}$ and rarely within the bones. ${ }^{5}$ Even dedifferentiated variants have been described. ${ }^{6}$ Early studies reported a better overall prognosis than that for conventional chondrosarcomas, ${ }^{2}$ but long-term studies have shown the contrary. ${ }^{7,8}$

Correspondence: Dr T Aigner, Cartilage Research, Institute of Pathology, University of Erlangen-Nürnberg, Krankenhausstr. 810, D-91054, Erlangen, Germany

${ }^{*}$ Current address: Department of Pathology, Brigham and Women's Hospital, Boston, MA, USA.

Received 12 May 2003; revised 13 August 2003; accepted 18 August 2003; published online 5 December 2003
The histopathologic spectrum of extraskeletal myxoid chondrosarcoma ranges from lesions with densely packed rounded cells to those composed of cords of cells and lesions with focal cartilage formation. ${ }^{2}$ This cartilage formation, the originally reported positivity for S-100 protein, ${ }^{9-15}$ and the ultrastructural resemblance of the neoplastic cells to chondroblasts $^{13,16}$ were the source of the term 'extraskeletal myxoid chondrosarcoma' for this type of soft-tissue tumor. ${ }^{17}$ However, most extraskeletal myxoid chondrosarcomas do not show chondroid tissue formation. ${ }^{2,3,15}$ Also, S-100 protein positivity is found much less commonly than was reported originally. ${ }^{3,7,18,19}$ Both observations cast doubt on the histogenetic classification of these lesions as chondroblastic entities. Additionally, the relationship between extraskeletal and skeletal myxoid chondrosarcoma is unclear, ${ }^{3}$ and molecular and ultrastructural evidence suggests both being completely different tumor entities. ${ }^{3,18}$

Chondrogenic differentiation in fetal development, ${ }^{20,21}$ in adult secondary chondrogenesis, ${ }^{22}$ and in chondrogenic neoplasms ${ }^{23-26}$ can be identified and monitored by investigating marker genes of 
chondrocytic differentiation such as collagen subtypes. In particular, collagen types II and X are distinct markers for the chondrocytic cell lineage (for a review see Cancedda et $a l^{27}$ ). Positivity for collagen types I, III, and VI indicates a fibroblastic phenotype, whereas the presence of type I collagen alone suggests an osteoblastic cell type. The presence of aggrecan, another typical gene product of chondrocytic cells, is, however, not a specific marker but also occurs in noncartilaginous tissues and nonchondrocytic neoplasms such as chondroblastoma. ${ }^{25}$ This neoplasm, formerly suggested to be of chondroid origin due to 'pink-chondroid' tumor areas, failed to express collagen type II, the main marker of chondrocytic differentiation, in our analyses. Also the expression of S-100 protein was not correlated with areas of assumptive chondrogenesis.

In this study, we investigated the presence of various matrix genes in a representative series of extraskeletal myxoid chondrosarcomas to determine the cellular phenotype of these neoplasms. Using this approach, we previously identified or rejected real neoplastic chondrogenesis independent of morphological appearance in lesions of uncertain origin such as chondroblastomas, ${ }^{25}$ mesenchymal chondrosarcomas, ${ }^{26}$ chondromyxoid fibromas, ${ }^{28}$ and clear cell chondrosarcomas. ${ }^{23}$ Thus, for example, chondroblastomas were found to lack chondroid differentiation mainly as they do not express collagen type II, the main marker of chondrocytic differentiation. Also, the expression of S-100 protein was not correlated with areas of assumptive chondrogenesis.

\section{Materials and methods}

\section{Tissue Preparation and Histology}

The specimens were derived from tumors of 14 patients with a diagnosis of myxoid chondrosarcoma of the soft tissues. The tumors were identified from the Mayo Clinic Tissue Registry/Soft Tissue and Bone Sarcoma Database according to established criteria described previously. ${ }^{29}$ The material was fixed with $10 \%$ formalin and embedded in paraffin. Paraffin sections ( $4-\mu \mathrm{m}$ thick) were cut and stored at room temperature until use.

\section{Histomorphological and Histochemical Detection of Mucopolysaccharide Content}

The histomorphological characteristics of the tumor specimens were evaluated by conventional hematoxylin-eosin staining. The content of mucopolysaccharide in the extracellular tumor matrix was demonstrated by toluidine blue staining. The content of collagens in the extracellular tumor matrix was demonstrated by Masson-Goldner staining.

\section{Immunohistochemical Analysis}

Deparaffinized sections were enzymatically pretreated, incubated with primary antibodies (Table 1) overnight at $4^{\circ} \mathrm{C}$, and visualized with use of a streptavidin-biotin complex technique (Super Sensitive Immunodetection System for mouse and rabbit primary antibodies; BioGenex, Mainz, Germany) with alkaline phosphatase as the detection enzyme and 3-hydroxy-2-naphthylacid 2,4-dimethylanilid as the substrate. Nuclei were counterstained with hematoxylin.

As specificity control for immunohistochemical stainings, samples of human fetal growth plate cartilage were stained in parallel. As negative control, the primary antibody was replaced by nonimmune mouse or rabbit serum (BioGenex, San Ramon, CA, USA) or Tris-buffered saline (pH 7.2) on control sections.

\section{Results}

Histologically, extraskeletal myxoid chondrosarcomas showed the typical features previously described $^{11,29}$ (Table 2) (Figures 1a and 2a). All specimens showed somewhat cellular lesions with neoplastic cells in a mucous matrix. Only part of one specimen (case 5) (Figure 2) showed histologically overt cartilage matrix formation with rounded chondrocyte-like cells embedded in cartilage-typical lacunae (Figure 2b). In accordance with the literature, ${ }^{2}$ mitotic activity tended to be low, and only occasional mitotic figures were found.

\section{Proteoglycan Histochemistry and Immunohistochemistry}

Histochemically, only weak metachromatic staining for glycosaminoglycans was obtained with use of toluidine blue staining (Figure 1b). The only exception was specimen 5 , which showed moderate to abundant metachromatic staining for glycosaminoglycans in the chondroid tumor areas (Figure 2c). Immunostaining of aggrecan core protein was completely absent in $71 \%$ of specimens (10/14) (Figure 1c) or was observed only focally within the tumor matrix in 29\% of the specimens (4/14) (Figure $1 \mathrm{~d})$. Only the chondroid areas of specimen 5 showed strong staining for aggrecan core protein throughout the tumor matrix (Figure 2d). The nonchondroid (ie, myxoid) areas of this lesion were morphologically indistinguishable from those of the other extraskeletal myxoid chondrosarcomas and were also negative histochemically for glycosaminoglycans and immunohistochemically for aggrecan.

\section{Collagen Histochemistry and Immunohistochemistry}

Histochemically, only weak staining for collagens was obtained with use of Masson-Goldner staining 
Table 1 Primary antibodies and enzymatic pretreatments used for immunohistochemical analysis

\begin{tabular}{lllll}
\hline Antigen & Type & Dilution & Digestion & Source \\
\hline $\begin{array}{l}\text { S-100 protein } \\
\text { Collagen type }\end{array}$ & $\mathrm{r}$ & $1: 1000$ & $\mathrm{P}$ & Dako, Glostrup, Denmark \\
I & $\mathrm{r}$ & $1: 200$ & $\mathrm{H}, \mathrm{Pt}$ & Synbio, Berlin, Germany \\
II & $\mathrm{r}$ & $1: 50$ & $\mathrm{H}, \mathrm{P}$ & Novacastra, Peterborough, United Kingdom \\
III & $\mathrm{r}$ & $1: 5000$ & $\mathrm{H}, \mathrm{P}$ & Dr K Günzler, Aventis, Frankfurt, Germany \\
VI & $\mathrm{r}$ & $1: 5000$ & $\mathrm{H}, \mathrm{P}$ & Dr R Timpl, Munich, Germany \\
X & $\mathrm{m}$ & $1: 100$ & $\mathrm{H}, \mathrm{P}$ & Dr K von der Mark, Erlangen, Germany \\
Aggrecan & $\mathrm{m}$ & $1: 5000$ & $\mathrm{H}, \mathrm{Pt}$ & Dr R Perris, Avioli, Italy
\end{tabular}

$\mathrm{H}$, hyaluronidase (bovine testis in $2 \mathrm{mg} / \mathrm{ml}$, phosphate-buffered saline (PBS), $\mathrm{pH} 5,60 \mathrm{~min}$ at $37^{\circ} \mathrm{C}$ ); $\mathrm{m}$, mouse monoclonal; $\mathrm{P}$, pronase $(2 \mathrm{mg} / \mathrm{ml}$, PBS, pH 7.3, $60 \mathrm{~min}$ at $37^{\circ} \mathrm{C}$ [Boehringer, Mannheim, Germany]); Pt, protease XXIV $(0.02 \mathrm{mg} / \mathrm{ml}, \mathrm{PBS}, \mathrm{pH} 7.3,60$ min at room temperature (Sigma, Berlin, Germany)); r, rabbit polyclonal.

Table 2 Immunohistochemical reaction patterns in extraskeletal myxoid chondrosarcomas

\begin{tabular}{|c|c|c|c|c|c|c|c|c|c|c|}
\hline Specimen & HE-chondroid & GAGs & Agg & Col & Col I & Col II & Col III & Col VI & $\operatorname{Col} X$ & $S-100$ \\
\hline 1 & 0 & 2 & ff3 & $0-1$ & 2 & 0 & 1 & 2 & 0 & f2 \\
\hline 2 & 0 & 2 & 0 & $0-1$ & 2 & 0 & 1 & F2 & 0 & f2 \\
\hline 3 & 0 & 2 & 0 & $1-2$ & 3 & 0 & 2 & 3 & 0 & f3 \\
\hline 4 & 0 & F2 & f2 & 1 & 3 & 0 & 2 & 2 & 0 & 0 \\
\hline $5^{\mathrm{a}}$ & - & - & - & - & - & - & - & - & - & - \\
\hline Nonchondroid areas & 0 & 0 & 0 & 1 & $1-3$ & 0 & 2 & it & 0 & f2 \\
\hline Chondroid areas & 3 & 3 & 3 & 2 & 1 & 3 & $1-2$ & pc & 0 & 3 \\
\hline 6 & 0 & 2 & f3 & 1 & $2-3$ & 0 & $1-2$ & 2 & 0 & f2 \\
\hline 7 & 0 & 2 & $\mathrm{f} 1$ & 1 & $1-3$ & 0 & 2 & 2 & 0 & f3 \\
\hline 8 & 0 & 0 & 0 & 1 & $1-2$ & 0 & 2 & 1 & 0 & ff2 \\
\hline 9 & 0 & 0 & 0 & 1 & 2 & 0 & $2-3$ & $1-2$ & 0 & 0 \\
\hline 10 & 0 & $2-3$ & 0 & 1 & $2-3$ & 0 & 2 & 2 & 0 & 0 \\
\hline 11 & 0 & 1 & 0 & $0-1$ & $1-2$ & 2 & $2-3$ & $0-2$ & 0 & f2 \\
\hline 12 & 0 & 0 & 0 & 1 & $1-3$ & 0 & 2 & $2-3$ & 0 & 0 \\
\hline 13 & 0 & 1 & 0 & 1 & 2 & 0 & 3 & $1-2$ & 0 & ff2 \\
\hline 14 & 0 & $1-2$ & 0 & 1 & 2 & 0 & 2 & 2 & 0 & ff1 \\
\hline
\end{tabular}

Agg, aggrecan; Col, collagen content as estimated by Masson-Goldner stain; Col I, II, III, VI, and X, collagen types I, II, III, VI, and X; f, focally (less than $25 \%$ of the tumor); ff, very few cells (less than $2 \%$ ); GAGs, glycosaminoglycans as shown by toluidine blue staining; HE, hematoxylin-eosin; it, interterritorial staining (ie staining throughout the matrix); pc, pericellular staining; S-100, S-100 protein. Staining intensity: 3, strong; 2 , moderate; 1 , weak; 0 , no staining.

See text.

(Figure 1e). The only exception again was specimen 5 , which showed moderate collagen staining in the chondroid tumor areas (Figure 2e). None of the extraskeletal myxoid chondrosarcomas showed any presence of collagen type II (Figure 1f) except specimen 5 in the chondroid areas (Figure 2f) and specimen 12, which showed no morphological signs of chondroid tissue formation. None of the samples expressed collagen type $\mathrm{X}$, including the chondroid areas of specimen 5 (Figure 2g). Collagen types I, III, and VI were diffusely positive in all cases within the extracellular tumor matrix (Figure 1g-i). Of note, in the chondroid areas of specimen 5 that expressed collagen type II and showed chondrocytic cells lying in lacuna-like matrix spaces, collagen type VI was concentrated in the pericellular matrix (Figure 2h). In addition, less collagen types I and III were found in the tumor matrix. In the nonchondroid portion of this specimen, collagen type VI was observed throughout the intercellular tumor matrix, together with collagen types I and III, as in all other cases.

\section{S-100 Protein Expression}

Most extraskeletal myxoid chondrosarcomas (9/14) showed signals for S-100 protein only focally $(<5 \%$ of cells) (Figure 1j) or not at all (5/14). In contrast, the chondroid areas of specimen 5 showed strong staining for S-100 protein (Figure 2i). In the nonchondroid areas of this specimen, similar to the other specimens, only focal signals for S-100 protein were found.

In all samples, the non-neoplastic nervous or fatty tissue was strongly positive for S-100 protein, thus representing an excellent internal positive control. 

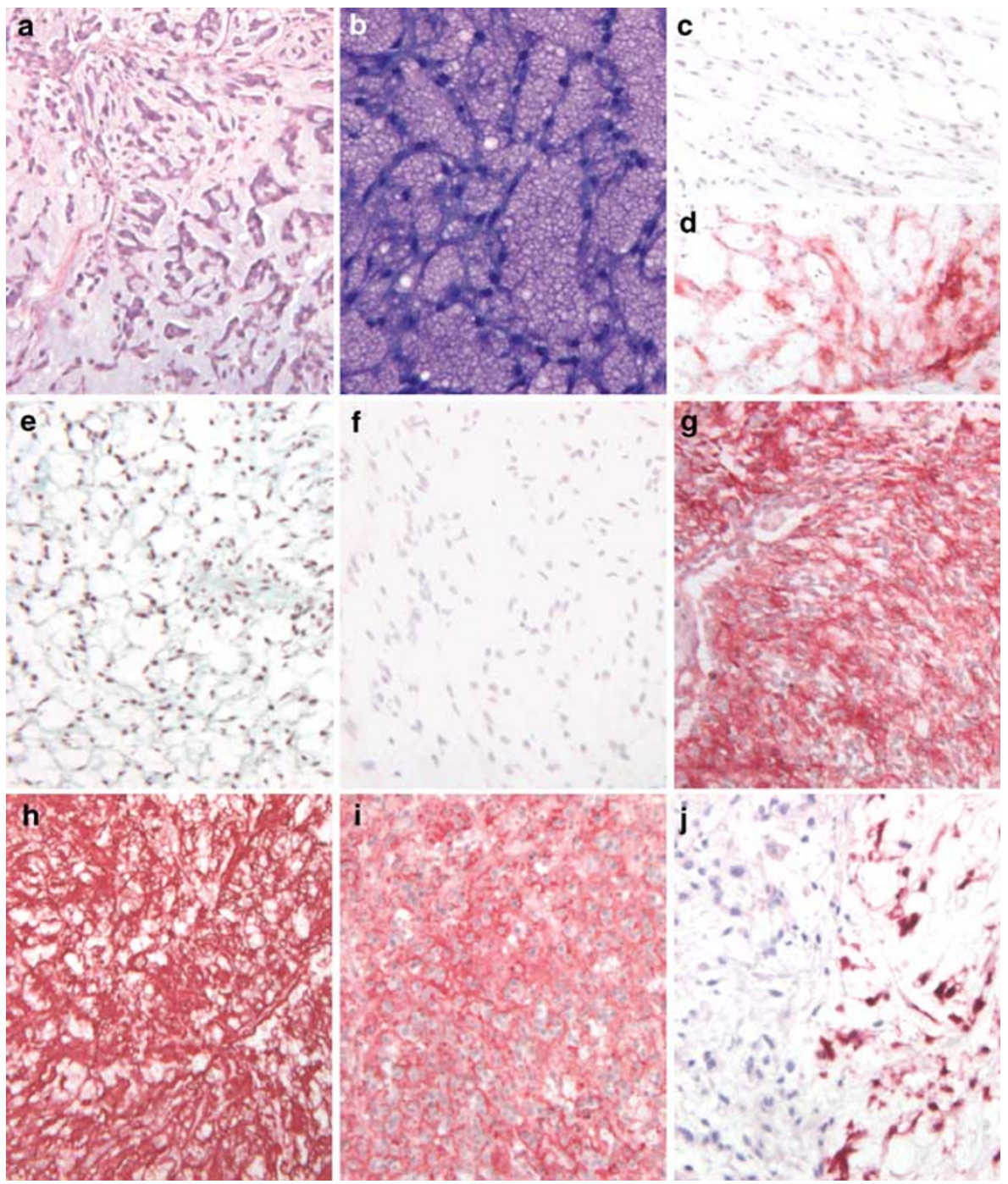

Figure 1 Extraskeletal myxoid chondrosarcoma shows classically neoplastic cells often lying in cord-like arrangements within mucous tumor matrix (a, hematoxylin-eosin staining), which shows hardly any proteoglycans (b, toluidine blue staining; c, d: immunostainings for proteoglycan aggrecan). Staining for collagens (b, Masson-Goldner staining) was also very weak and no type II collgean could be detected immunohistochemically (f). In contrast, collagen types I (g), III (h), and VI (i) were found multifocally in the intercellular tumor matrix. S-100 protein was seen only focally in the cells of extraskeletal myxoid chondrosarcomas (j).

\section{Discussion}

The main result of this study was that only two of 14 extraskeletal myxoid chondrosarcoma specimens showed signs of chondrocytic differentiation. This was shown not only histomorphologically ${ }^{15}$ but also at the cellular level, as indicated by the absence of collagen type II in all except the two specimens. This was further stressed by the absence of S-100 protein in most tumor cells of extraskeletal myxoid chondrosarcoma, a marker rather consistently present in neoplastic chondrocytes. ${ }^{26,30,31}$ In addition, aggrecan, another typical gene product of chondrocytes, was not found in extraskeletal myxoid chondrosarcomas. However, one extraskeletal myxoid chondrosarcoma specimen, identical in most areas to the others examined, showed focal areas of chondroid differentiation. This was proven not only by histomorphological appearance but also at the cellular level by using collagen type II, aggrecan core protein, and S-100 protein as markers of chondrocytic cell differentiation. These findings agree with those of previous studies that demonstrated collagen type II expression in single examples of extraskeletal myxoid chondrosarcoma. ${ }^{12,13}$ Collagen type X, a marker of terminal chondrocytic maturation and differentiation in fetal growth plate cartilage, ${ }^{32}$ was absent in all investigated samples, suggesting the absence of full chondrocytic differentiation capacity of extraskeletal myxoid chondrosarcomas. This and the lack of cartilage formation in extraskeletal myxoid chondrosarcoma explain why calcification, which occurs in other chondrosarcomatous entities, is not a feature of extraskeletal myxoid 

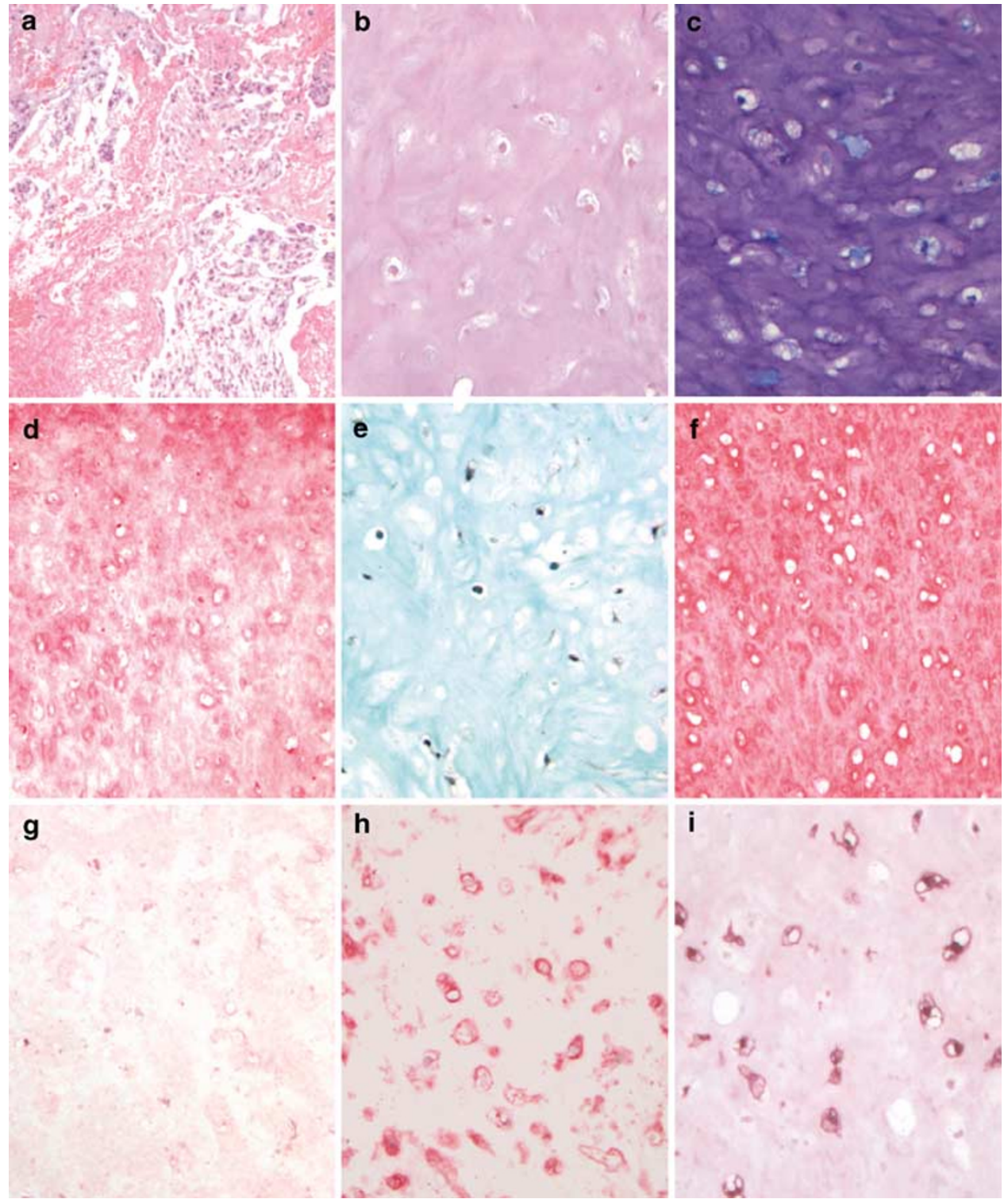

Figure 2 One extraskeletal myxoid chondrosarcoma showed areas of classical morphology (a, hematoxylin-eosin (HE) staining) and areas of overt chondroid differentiation (b, HE staining). The chondroid areas showed abundant glycosaminoglycan-positive (c, toluidine blue staining; d: immunostaining for aggrecan proteoglycan) and collagen-positive (e, Masson-Goldner staining) tumor matrix. Immunohistochemically, collagen type II (f), but not type X collagen (g) was shown in the interterritorial tumor matrix, whereas type VI collagen was concentrated pericellularly (h). S-100 protein was strongly positive in nearly all cells of the chondroid tumor areas (i).

chondrosarcomas, ${ }^{17}$ because collagen type X expression is known to correlate with cartilage matrix calcification. ${ }^{32,33}$ This does not exclude dystrophic calcification in areas of tissue necrosis, which might occur in any neoplasm.

The presence of interstitial collagen types I, III, and VI in various amounts in extraskeletal myxoid chondrosarcomas in a basically mucin-rich, collagen-poor tumor matrix supports the idea of extraskeletal myxoid chondrosarcomas having a (primitive) mesenchymal phenotype, which is also indicated by their vimentin positivity. ${ }^{29}$ These results specify biochemically previous ultrastructural findings that described the extracellular matrix of extraskeletal myxoid chondrosarcoma as consisting mainly of amorphous material with few collagen fibrils. ${ }^{16}$ Our findings indicate that these fibrils are composed mainly of collagen types I and III. The fine fibrillar networks between them seem to consist, at least in part, of collagen type VI. Our study could not confirm previous reports of the extensive presence of cartilage-typical proteoglycans within extraskeletal myxoid chondrosarcomas. ${ }^{12}$ Although histochemical staining for glycosaminoglycans occurred, ${ }^{11}$ it was weak ${ }^{15}$ compared with the staining evident in physiologic and neoplastic cartilages. ${ }^{26,34,35}$ Most importantly, immunolocalization did not demonstrate cartilage- 
typical aggrecan in most tumor areas. This was not the case in the chondroid areas of specimen 5, which showed both clear metachromasia and aggrecan immunostaining. Other mucins such as decorin, biglycan, or versican, which occur in cartilage and are also present in many other tissues, ${ }^{36,37}$ may occur in the extracellular matrix of extraskeletal myxoid chondrosarcoma. The presence of other mucins may explain as to why most authors reported hyaluronidase resistance of histochemical staining, ${ }^{2,11}$ which does not fit with the presence of the hyaluronan-bound cartilage proteoglycan aggrecan.

Our results indicate that the basic cellular phenotype of extraskeletal myxoid chondrosarcoma is not chondrocytic or prechondrocytic. Also the classification of primitive or undifferentiated mesenchymal cells as chondroblastic by electron microscopy has to be considered with caution, ${ }^{16}$ as demonstrated recently for chondroblastomas. ${ }^{25}$ Chondroblastomas do not show chondroblastic differentiation despite morphological and ultrastructural resemblance to chondroblastic cells. ${ }^{38,39}$ This is in contrast to mesenchymal chondrosarcoma, a neoplasm we recently identified as the prototypic lesion of chondroprogenitor cells. ${ }^{26}$ Thus, extraskeletal myxoid chondrosarcoma cells must be considered to display an undifferentiated mesenchymal phenotype without a single specific differentiation. In extraskeletal myxoid chondrosarcomas, multidirectional differentiation of cells occurs, which is documented by the focal positivity for many different cell differentiation markers such as epithelial membrane antigen, epithelial cytokeratins, S-100 protein, and neuron-specific enolase..$^{9,18,40,41}$ This is further supported at the histomorphological level because numerous specimens exhibit areas with morphological features similar to those of other tumors such as synovial sarcoma, fibrosarcoma, rhabdoid tumor, and other poorly differentiated lesions. ${ }^{7,42}$ The common presence of neuroendocrine differentiation in extraskeletal myxoid chondrosarcoma ${ }^{12,18,19}$ further supports the presence of a cellular phenotype not restricted to the chondrocytic cell lineage.

An important issue concerning the diagnosis of soft tissue lesions is accurate identification of the tumor type. ${ }^{11}$ For example, the distinction between extraskeletal myxoid chondrosarcomas and myxoid variants of chondrosarcoma may be difficult. However, the cell biology and tumor matrix biochemistry of these two histologically similar neoplasms are much different. Myxoid areas of conventional chondrosarcomas strongly express aggrecan ${ }^{34,43}$ and, at least focally, collagen types II and X, features not seen in extraskeletal myxoid chondrosarcoma. ${ }^{24,34}$ The difference between these two types of neoplasms is also evident at the genetic level. Myxoid variants of skeletal chondrosarcomas do not show the chromosomal translocations found typically in extraskeletal myxoid chondrosarco- mas. ${ }^{7,42}$ Another tumor that may be difficult to distinguish from extraskeletal myxoid chondrosarcoma is chordoma. ${ }^{9,10}$ Chordomas show even stronger aggrecan positivity than extraskeletal myxoid chondrosarcomas and in many cases positivity for cartilage collagen type II even in the absence of ouvert cartilage formation. ${ }^{44}$ Chordomas are also strongly positive for S-100 and epithelial cytokeratins and EMA throughout the lesion. The matrix gene pattern in extraskeletal myxoid chondrosarcomas distinguishes them from soft-tissue chondromas.

In summary, extraskeletal myxoid chondrosarcoma is a tumor entity different from any myxoid variant of conventional chondrosarcoma, mesenchymal chondrosarcoma, and chordoma. The specific differences are not only its clinicopathologic and genetic features ${ }^{7,41}$ but also the characteristics of its cell and tumor matrix. Extraskeletal myxoid chondrosarcoma consists most likely of primitive mesenchymal cells ${ }^{45}$ with focal, multidirectional differentiation with chondrocytic differentiation being an unusual but histomorphologically the most obvious differentiation pathway.

\section{Acknowledgements}

We are grateful to Mrs S Fickenscher and Olga Reimer for expert technical support. This work was supported by the Wilhelm Sander-Stiftung (Munich, Germany; Grant 96.050.3).

\section{References}

1 Stout AP, Verner EW. Chondrosarcoma of the extraskeletal soft tissues. Cancer 1953;6:581-590.

2 Enzinger FM, Shiraki M. Extraskeletal myxoid chondrosarcoma. An analysis of 34 cases. Hum Pathol 1972;3:421-435.

3 Antonescu CR, Argani P, Ealey JH, et al. Skeletal and extraskeletal myxoid chondrosarcoma. Cancer 1998; 83:1504-1521.

4 Kindblom LG, Angervall L. Myxoid chondrosarcoma of the synovial tissue. A clinicopathologic, histochemical, and ultrastructural analysis. Cancer 1983;52: 1886-1895.

5 Kilpatrick SE, Inwards CY, Fletcher CD, et al. Myxoid chondrosarcoma (chordoid sarcoma) of bone: a report of two cases and review of the literature. Cancer 1997;79:1903-1910.

6 Ramesh K, Gahukamble L, Sarma NH, et al. Extraskeletal myxoid chondrosarcoma with dedifferentiation. Histopathology 1995;27:381-382.

7 Meis-Kindblom JM, Bergh P, Gunterberg B, et al. Extraskeletal myxoid chondrosarcoma. Am J Surg Pathol 1999;23:636-650.

8 Saleh G, Evans HL, Ro JY, et al. Extraskeletal myxoid chondrosarcoma. A clinicopathologic study of ten patients with long-term follow-up. Cancer 1992;70:2827-2830. 
9 Abramovici LC, Steiner GC, Bonar F. Myxoid chondrosarcoma of soft tissue and bone: a retrospective study of 11 cases. Hum Pathol 1995;26:1215-1220.

10 Fletcher CD, McKee PH. Immunohistochemistry and histogenesis of extraskeletal myxoid chondrosarcoma. J Pathol 1985;147:67-68.

11 Fletcher CD, Powell G, McKee PH. Extraskeletal myxoid chondrosarcoma: a histochemical and immunohistochemical study. Histopathology 1986;10:489-499.

12 Harris M, Coyne J, Tariq M, et al. Extraskeletal myxoid chondrosarcoma with neuroendocrine differentiation: a pathologic, cytogenetic, and molecular study of a case with a novel translocation $\mathrm{t}(9 ; 17)(\mathrm{q} 22 ; \mathrm{q} 11.2)$. Am J Surg Pathol 2000;24:1020-1026.

13 Sato K, Kubota T, Yoshida K, et al. Intracranial extraskeletal myxoid chondrosarcoma with special reference to lamellar inclusions in the rough endoplasmic reticulum. Acta Neuropathol (Berl) 1993; 86:525-528.

14 Tos APD, Wadden C, Fletcher CDM. Extraskeletal myxoid chondrosarcoma: an immunohistochemical reappraisal of 39 cases. Appl Immunohistochem 1997; 5:73-77.

15 Vilanova JR, Simon-Marin R, Burgos-Bretones J, et al. Non-conventional chondrosarcomas and chondrogenesis. Histopathology 1985;9:719-728.

16 Smith MT, Farinacci CJ, Carpenter HA, et al. Extraskeletal myxoid chondrosarcoma: a clinicopathological study. Cancer 1976;37:821-827.

17 Weiss SW, Goldblum JR. Extraskeletal myxoid chondrosarcoma. In: Weiss SW, Goldblum JR (eds). Soft Tissue Tumors, 4th edn. Mosby: St. Louis, 2001, pp. 1368-1378.

18 Goh YW, Spagnolo DV, Platten M, et al. Extraskeletal myxoid chondrosarcoma: a light microscopic, immunohistochemical, ultrastructural and immunoultrastructural study indicating neuroendocrine differentiation. Histopathology 2001;39:514-524.

19 Okamoto S, Hisaoka M, Ishida T, et al. Extraskeletal myxoid chondrosarcoma: a clinicopathologic, immunohistochemical, and molecular analysis of 18 cases. Hum Pathol 2001;32:1116-1124.

20 Sandberg M, Vuorio E. Localization of types I, II, and III collagen mRNAs in developing human skeletal tissues by in situ hybridization. J Cell Biol 1987; 104:1077-1084.

21 Vornehm SI, Dudhia J, von der Mark K, et al. Expression of collagen types IX and XI as well as other major cartilage matrix components by human fetal chondrocytes in vivo. Matrix Biol 1996;15: 91-98.

22 Aigner T, Dietz U, Stö $\beta$ H, et al. Differential expression of collagen types I, II, III, and X in human osteophytes. Lab Invest 1995;73:236-243.

23 Aigner T, Dertinger S, Belke J, et al. Chondrocytic cell differentiation in clear cell chondrosarcoma. Hum Pathol 1996;27:1301-1305.

24 Aigner T, Frischholz S, Dertinger S, et al . Type X collagen expression and hypertrophic differentiation in chondrogenic neoplasms. Histochem Cell Biol 1997; 107:435-440.

25 Aigner T, Loos S, Inwards CY, et al . Chondroblastoma is an osteoid-forming, but not cartilage-forming neoplasm. J Pathol 1999;189:463-469.

26 Aigner T, Loos S, Müller S, et al . Cell differentiation and matrix gene expression in mesenchymal chondrosarcomas. Am J Pathol 2000;156:1327-1335.
27 Cancedda R, Descalzi-Cancedda F, Castagnola P. Chondrocyte differentiation. Int Rev Cytol 1995;159: 265-358.

28 Söder S, Inwards CY, Müller S, et al. Cell biology and matrix biochemistry of chondromyxoid fibroma. Am J Clin Pathol 2001;116:271-277.

29 Oliveira AM, Sebo TJ, McGrory JE, et al. Extraskeletal myxoid chondrosarcoma: a clinicopathologic, immunohistochemical, and ploidy analysis of 23 cases. Mod Pathol 2000;13:900-908.

30 Nakamura Y, Becker LE, Marks A. S-100 protein in tumors of cartilage and bone. Cancer 1983;52: 1820-1824.

31 Stefansson K, Wollmann RL, Moore BW, et al. S-100 protein in human chondrocytes. Nature 1982;295: 63-64.

32 Reichenberger E, Aigner T, von der Mark K, et al. In situ hybridization studies on the expression of type $\mathrm{X}$ collagen in fetal human cartilage. Dev Biol 1991; 148:562-572.

33 Linsenmayer TF, Chen Q, Gibney E, et al. Collagen types IX and $\mathrm{X}$ in the developing chick tibiotarsus: analyses of mRNAs and proteins. Development 1991;111:191-196.

34 Aigner T, Dertinger S, Vornehm SI, et al. Phenotypic diversity of neoplastic chondrocytes and extracellular matrix gene expression in cartilaginous neoplasms. Am J Pathol 1997;150:2133-2141.

35 Aigner T, Vornehm SI, Zeiler G, et al. Suppression of cartilage matrix gene expression in upper zone chondrocytes of osteoarthritic cartilage. Arthritis Rheum 1997;40:562-569.

36 Bode-Lesniewwska B, Dours-Zimmermann MT, Odermatt BF, et al. Distribution of the large aggregating proteoglycan versican in adult human tissues. J Histochem Cytochem 1996;44:303-312.

37 Hardingham TE, Fosang AJ. Proteoglycans: many forms and many functions. FASEB J 1992;6:861-870.

38 Fadda M, Manunta A, Rinonapoli G, et al. Ultrastructural appearance of chondroblastoma. Int Orthop 1994;18:389-392.

39 Levine GD, Bensch KG. Chondroblastoma - the nature of the basic cell. Cancer 1972;29:1546-1562.

40 Folpe AL, Agoff SN, Willis J, et al. Parachordoma is immunohistochemically and cytogenetically distinct from axial chordoma and extraskeletal myxoid chondrosarcoma. Am J of Surg Pathol 1999;23: 1059-1067.

41 Rubin BP, Fletcher JA. Skeletal and extraskeletal myxoid chondrosarcoma: related or distinct tumors? Adv Anat Pathol 1999;6:204-212.

42 Brody RI, Ueda T, Hamelin A, et al. Molecular analysis of the fusion of EWS to an orphan nuclear receptor gene in extraskeletal myxoid chondrosarcoma. Am J Pathol 1997;150:1049-1058.

43 Aigner T, Dertinger S, Neureiter D, et al. De-differentiated chondrosarcoma is not a 'de-differentiated' chondrosarcoma. Histopathology 1998;33:11-19.

44 Gottschalk D, Fehn M, Patt S, et al. Matrix gene expression analysis and cellular phenotyping in chordoma reveals focal differentiation pattern of neoplastic cells mimicking nucleus pulposus development. Am J Pathol 2001;158:1571-1578.

45 Yasuda T, Poole AR. A fibronectin fragment induces type II collagen degradation by collagenase through an interleukin-1-mediated pathway. Arthritis Rheum 2002;46:138-148. 
46 Specks U, Mayer U, Nischt R, et al. Structure of recombinant N-terminal globule of type VI collagen $\alpha 3$ chain and its binding to heparin and hyaluronan. EMBO J 1992;11:4281-4290.
47 Girkontaité I, Frischholz S, Lammi P, et al. Immunolocalization of type $\mathrm{X}$ collagen in normal fetal and adult osteoarthritic cartilage with monoclonal antibodies. Matrix Biol 1996;15:231-238. 